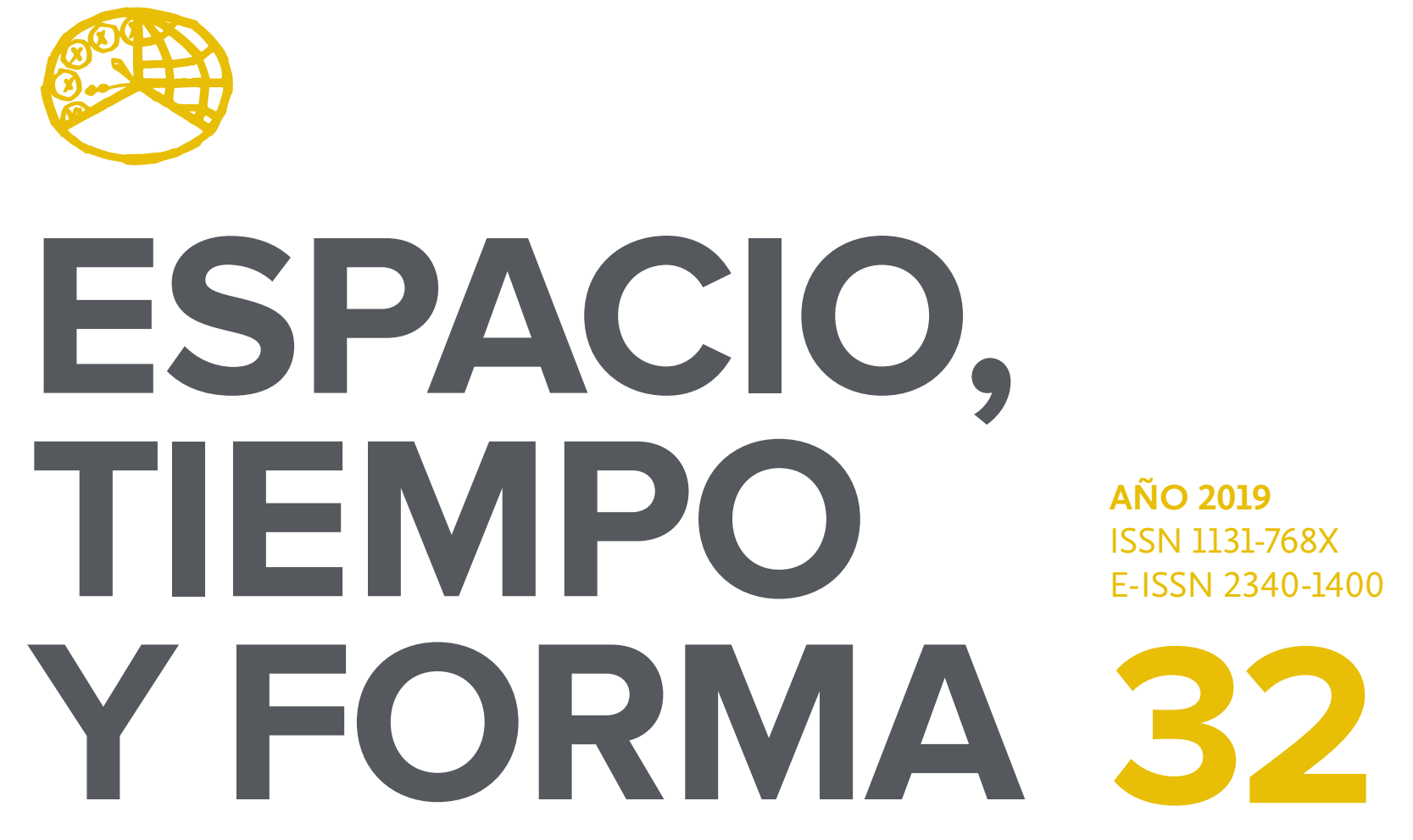

SERIE IV HISTORIA MODERNA

REVISTA DE LA FACULTAD DE GEOGRAFÍA E HISTORIA 


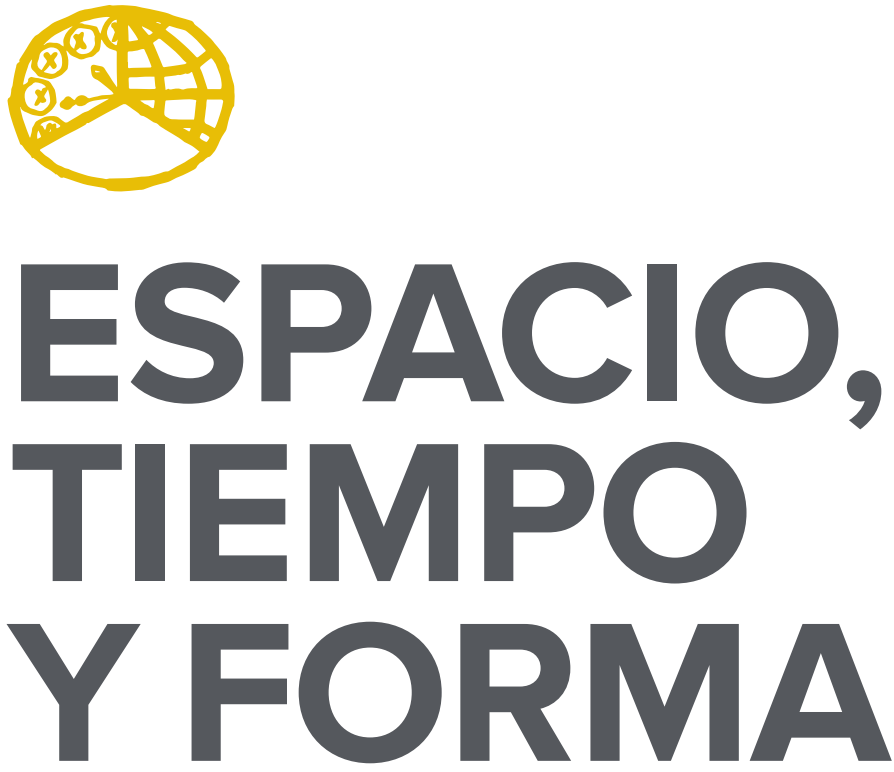

AÑO 2019

ISSN 1131-768X

E-ISSN 2340-1400

SERIE IV HISTORIA MODERNA

REVISTA DE LA FACULTAD DE GEOGRAFİA E HISTORIA

DOI: http://dx.doi.org/10.5944/etfiv.32.2019

\section{UกED}

UNIVERSIDAD NACIONAL DE EDUCACIÓN A DISTANCIA 
La revista Espacio, Tiempo y Forma (siglas recomendadas: ETF), de la Facultad de Geografía e Historia de la UNED, que inició su publicación el año 1988, está organizada de la siguiente forma:

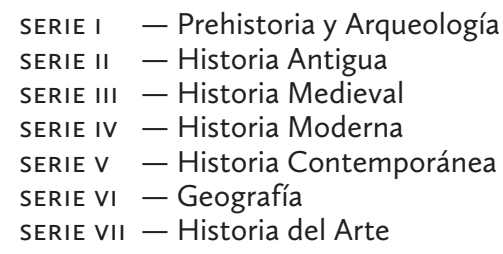

Excepcionalmente, algunos volúmenes del año 1988 atienden a la siguiente numeración:

$$
\begin{aligned}
& \mathrm{N}^{\circ} 1 \text { - Historia Contemporánea } \\
& \mathrm{N}^{\circ} 2 \text { - Historia del Arte } \\
& \mathrm{N}^{\circ} 3 \text { - Geografía } \\
& \mathrm{N} .^{\circ} 4 \text { - Historia Moderna }
\end{aligned}
$$

ETF no se solidariza necesariamente con las opiniones expresadas por los autores.

\author{
UNIVERSIDAD NACIONAL DE EDUCACIÓN A DISTANCIA \\ Madrid, 2019 \\ SERIE IV · HISTORIA MODERNA N. ${ }^{\circ} 32,2019$ \\ ISSN 1131-768X · E-ISSN 2340-1400 \\ DEPÓSITO LEGAL \\ M-21.037-1988 \\ URL \\ ETF IV · HISTORIA MODERNA · http://revistas.uned.es/index.php/ETFIV \\ DISEÑO Y COMPOSICIÓN \\ Carmen Chincoa Gallardo · http://www.laurisilva.net/cch \\ Impreso en España · Printed in Spain
}

(c) (1) (8) Esta obra está bajo una licencia Creative Commons Reconocimiento-NoComercial 4.0 Internacional. 


\section{MISCELÁNEA • MISCELLANY}





\title{
FIDELIDAD, FUEROS Y NEGOCIACIÓN. LAS CORTES DE SANGÜESA EN LA DEFENSA DE LA CORONA DE ARAGÓN (1705)
}

\section{LOYALTY, FUEROS AND NEGOTIATION. THE CORTES OF SANGÜESA IN THE DEFENSE OF THE CROWN OF ARAGON (1705)}

\author{
Aitor Díaz Paredes ${ }^{1}$ \\ Recibido: 29/08/2018 - Aceptado: 13/11/2018 \\ Doi: http://dx.doi.org/10.5944/etfiv.2019.22466
}

\section{Resumen}

En el verano de I705, España se encontraba al borde de una guerra civil. La Monarquía Hispánica, en previsión a un desembarco Aliado en Cataluña, se vio obligada a desviar recursos al frente mediterráneo. Felipe $\mathrm{V}$ necesitaba tropas, y convocó Cortes en Navarra. Navarra era un territorio leal, pero que mantenía sus propias instituciones políticas -las Cortes y la Diputación-, y su propio sistema fiscal y jurídico -el Fuero General-. Estas particularidades habían mantenido a Navarra al margen de la costosa política exterior de los Habsburgo. Ahora, sin embargo, la situación había cambiado, y la Monarquía tenía que negociar con las Cortes un servicio, en forma de regimientos.

\section{Palabras clave}

Guerra de Sucesión Española; Monarquía Hispánica; Reclutamiento; Navarra; Fueros.

\begin{abstract}
In the summer of 1705 , Spain was about to face civil war. In the eventuality of an Allied landing in Catalonia, the Crown was forced to divert resources to the Mediterranean front. Philip V needed troops, and he called the three estates of Navarre for Cortes. Navarre was a loyal territory, but it had its own political institutions -the Cortes and its permanent commission, the Diputación- and its own tax and juridical system -the Fuero General-. These particularities kept Navarre out of the
\end{abstract}

\footnotetext{
1. Universidad de Navarra. C. e.: adiaz.3@alumni.unav.es

Este trabajo forma parte del proyecto de investigación «Los nervios de la guerra. Movilización de recursos militares y construcción de la monarquía imperial hispánica en los siglos XVII y XVIII» (HAR2015-64165-C2-1-P)» financiado por el Ministerio de Economía y Competitividad. Abreviaturas: Archivo Histórico Nacional (AHN): Estado (E); Biblioteca Nacional (BNE); Real Academia de la Historia (RAH); Archivo Real y General de Navarra (ARGN): Guerra (G); Archivo Municipal de Estella (AME); Archivo Municipal de Pamplona (AMP); Legajo (leg.), manuscrito (ms.), carpeta (c.).
} 
gruelling Habsburg foreign policy. However, the situation was now different, and the Monarchy had to negotiate with the Cortes a servicio, in the form of regiments.

Keywords

War of the Spanish Succession; Hispanic Monarchy; Recruitment; Navarre; Fueros. 


\section{ARMAR AL REY: LA CAMPAÑA RECLUTADORA DE 1705}

En I705, el virrey marqués de Solera pedía a las Cortes de Navarra, reunidas en Sangüesa, el mayor impôt du sang al que estas se habían tenido que enfrentar, resuelto finalmente bajo la forma de tres regimientos de infantería. La escala de dicho servicio era excepcional en comparación con similares situaciones acontecidas durante el siglo XVII, pero se inscribía dentro de la amplia campaña reclutadora iniciada por el gobierno borbónico en un momento crítico para la suerte de Felipe $\mathrm{V}$ ante el fracaso de la campaña de Portugal de I704 y la pérdida de Gibraltar. La implicación de Navarra en dicho reclutamiento y el apoyo al bando felipista tienen, por necesidad, que ponerse en relación con la situación global de la Monarquía Hispánica. La suma de crisis sucesoria y militar generaron una situación excepcional en Navarra, que se vio empujada a una guerra internacional de la cual no podía inhibirse. Lo que proponemos en este artículo es, a partir de dicha crisis global de la monarquía, analizar el proceso reclutador en un territorio como Navarra, con una serie de características propias, así como la puesta en práctica de dicho reclutamiento al integrarse en el ejército borbónico, desde su formación en Corella hasta el retorno de los regimientos a Tudela un año después de ser levantados.

Los años iniciales de la Guerra de Sucesión Española supusieron para la Monarquía un esfuerzo a gran escala para levantar regimientos o reforzar los ya existentes en el seno de un ejército que se encontraba en un proceso de reforma y reestructuración. Conviene subrayar que, no obstante, frente al tradicional derrotismo mostrado por la historiografía a la hora de abordar la deriva de las armas españolas durante el reinado de Carlos II, se impone una visión más amplia del problema. Así, se hace hincapié en las reformas acometidas en el ejército francés, en las ventajas logísticas con las que contaba Francia, en los múltiples escenarios donde la monarquía era atacada, o en la complejidad de la gran coalición en la que se encontraba inserta España durante las guerras contra Luis XIV, para explicar tanto la crisis sucesoria como la situación que hereda Felipe $V$ al llegar a Madrid ${ }^{2}$. Fueron precisamente las adversidades que tuvo que afrontar la Monarquía en su lucha contra una Francia geoestratégicamente mejor posicionada ${ }^{3}$, las que la empujaron a una continua adaptación a la evolución de la guerra, de manera que, si bien el escenario era cada vez más adverso, el ejército de las décadas finales del siglo XVII no estaba irremisiblemente condenado a la derrota ${ }^{4}$.

Con todo, el comienzo de la Guerra de Sucesión en Flandes y en Italia evidenció el tremuloso estado de los ejércitos españoles, y, en consecuencia, la necesidad de aumentar sus efectivos para poder enfrentarse a una nueva guerra, esta vez de consecuencias y alcance impredecibles. La apertura de un frente de guerra en Portugal y el desembarco en suelo peninsular de grandes contingentes de tropas enemigas aceleraron el reclutamiento a lo largo de la geografía española, tanto bajo

\footnotetext{
2. Rodríguez HeRnÁNDEZ, 2016b: 247-275.

. ROWLANDS, 2011: 492-514. CÉNAT, 2017: 47-61.

4. Rodríguez HernándeZ, 2009: 265-296; MAFFI, 2016: 111-128.
} 
la forma de milicias como de unidades regladas, especialmente en los territorios de la Corona de Castilla, entre I702 y I70 $5^{5}$. Estos cuerpos se componían preferentemente de soldados voluntarios, pero rara vez resultaba posible completar las unidades mediante este tipo de reclutas, viéndose las autoridades forzadas a recurrir al alistamiento de tropas de baja calidad, incluyéndose a vagabundos, convictos o soldados de cuota ${ }^{6}$. Ante la imposibilidad por parte del gobierno borbónico de levantar todos los hombres que necesitaba, se recurrió asimismo al reclutamiento por repartimiento, cuyo éxito se confiaba en la obligatoriedad de los cupos establecidos por las instituciones locales según la población estimada y la necesidad de hombres. Este mecanismo, que agilizaba la recluta e involucraba a las élites locales, era consecuentemente un mecanismo habitual en el seno de la Monarquía7.

Este procedimiento tenía especial implantación en los territorios forales, y daba comienzo una vez acordado el servicio que estos hacían a la Monarquía. Desafortunadamente, las garantías que daban a la Corona en cuanto al cumplimiento del número de soldados acordado y la agilidad del proceso, que recaía en las instituciones locales, tenían su contrapartida en la deficiente calidad e instrucción de los reclutas, pues las autoridades tenderían por defecto a deshacerse de los elementos más prescindibles de la comunidad. En estas ocasiones, la Monarquía era consciente de que, si bien el servicio prestado sería inferior a la petición real inicial, tras la negociación, se vería cumplido, lo cual era el objetivo primordial ${ }^{8}$. Estos territorios presentaban similitudes institucionales y procedimentales a la hora de reclutar, tal y como encontramos en Galicia ${ }^{9}$, Asturias ${ }^{\mathrm{IO}} \mathrm{o}$ las Provincias Vascas ${ }^{\mathrm{II}}$, repitiéndose el esquema de negociación y concesión de servicios de tropas a cambio de las patentes en blanco que implicaban el nombramiento de oficiales del país, unos cargos que se repartían entre las redes familiares y clientelares vinculadas al servicio a la Monarquía.

El ejercito heredado por Felipe V, pese a continuar siendo una agregación plurinacional de unidades ${ }^{12}$, experimentó con la «españolización» de la guerra un estrechamiento en la relación con la Corona y sus territorios peninsulares. Entre estos, se encontraba Navarra. Quintaesenciada en la exitosa trayectoria de una serie de financieros y asentistas locales, en su mayoría baztaneses ${ }^{13}$, adquiría una nueva dimensión, en la cual los militares navarros también supieron aprovechar esa «dinámica nacionalista» experimentada con el cambio dinástico ${ }^{14}$. La aportación de Navarra al esfuerzo bélico de la Monarquía durante la Guerra de Sucesión,

\footnotetext{
5. Este proceso de rearme ha sido profusamente analizado en las últimas décadas, véase CONTRERAS GAY, 1993: 13-44; Andújar Castillo, 2003: 53-74; De Castro Monsalve, 2004: 146-149; Albareda Salvadó, 2010: 248-250; Muñoz RodrígueZ, 2011: 141-145; SAAVEdRa VÁZQUeZ, 2014: 175-204.

6. Rodríguez HernándeZ, 2011: 162-173; StORRS, 2013: 84-87.

7. CONTRERAs GaY, 1994: 99-122.

8. RodrígueZ HeRnÁNDEZ, 2011: 224-225.

9. SaAvedra Vázquez, 2004: 679-700; Rodríguez Hernández, 2007: 213-251; Artaza Montero, $2016: 21-52$.

10. Martínez-Radío Garrido, 2008, 127-166.

11. Sánchez Belén, 1999: 249-274; Guerrero Elecalde, 2011: 309-337; Guerrero Elecalde, 2015: $167-178$.

12. Borreguero Beltrán, 2001: 53-90, Andújar CAStillo, 2004: 661-682, y 2003: 53-90; StOrRS, 2016: $24-27$.

13. GonZÁlez ENCISO, 2007: 13-59; TORRES SÁNCHEZ, 2016: 66-69.

14. ToRres SÁNCHEZ, 2010: 18.
} 
tanto en el papel jugado por los regimientos reclutados en las Cortes de 1705 como en los tercios provinciales de milicias, ha sido, sin embargo, ignorada. Tal ausencia historiográfica merece ser revisada, al realizar tanto los regimientos como las milicias una inestimable labor de contención y cobertura en el frente de Aragón para los ejércitos borbónicos ante las partidas austracistas. Igualmente, la escasez documental que ha dificultado el realizar una historia regimental de las diferentes unidades de la Monarquía durante la Guerra de Sucesión redunda en el interés de trazar el recorrido de los tres regimientos levantados en Navarra tras las Cortes celebradas en el verano de 1705 .

\section{UN REINO DENTRO DE UNA CORONA: RECLUTAR - Y NEGOCIAR- EN NAVARRA}

El proceso a través del cual Navarra aprobaba el servicio solicitado por el monarca implicaba a dos instituciones: la Monarquía, representada en la figura del virrey, Luis Francisco de Benavides y Aragón, IV marqués de Solera, y el Reino, representado en las Cortes. Las Cortes, por su parte, convocadas por, en este caso, Felipe V, quedaban integradas por los representantes de los tres brazos. El derecho de asistencia a Cortes era un acto de gracia real, sujeto a la voluntad y las necesidades del soberano, saliendo adelante las votaciones por mayoría simple, lo cual agilizaba la elaboración de leyes y la aprobación de servicios. La negociación inherente a la concesión de lo que necesitaba el monarca que convocaba las Cortes, permitía a los estados navarros jugar con ventaja frente a las urgencias del soberano. Entre las funciones de dichas Cortes, estaban la concesión de servicios a la Corona, bien mediante donativos, las figuras fiscales conocidas como cuarteles y alcabalas ${ }^{15}$, bien a través del reclutamiento de tercios o del levantamiento de milicias con fines de autodefensa ${ }^{16}$.

En momentos puntuales, se había solicitado a Navarra la formación de tercios, si bien Navarra, por su emplazamiento geográfico, cumplía funciones eminentemente defensivas y era, ante todo, receptora y no emisora de tropas. Su comprometida situación geográfica había evitado a Navarra una mayor implicación en las guerras libradas por la Monarquía, fruto de su condición fronteriza con el enemigo francés y de la protección que le otorgaban sus privilegios, y la contribución más continuada fue, de hecho, la que supuso el goteo de voluntarios enrolados en las sucesivas campañas de reclutamiento durante el siglo XVII ${ }^{17}$. Esto no fue impedimento para que se pidiese una mayor implicación en la guerra contra Francia para socorrer Guipúzcoa y Cataluña a lo largo de los reinados de Felipe IV y Carlos II $^{18}$. Esta presión, que corría paralela a la evolución y consolidación del propio Fuero General $^{19}$, asentó el marco negociador por el cual las Cortes concedían como servi-

15. SOlbes FerRI, 1993: 569-580.

16. Coloma García, 1995: 163-182; Martínez Ruiz, 2014: 343-349.

17. Rodríguez Hernández, Díaz Paredes, 2018: 265-275.

18. USUNÁRIZ GARAYOA, 2001: 685-744.

19. CoRONAS GONZÁLEZ, 2017: 73-86. 
cio al monarca el levantamiento de un tercio que pasaba a disolverse finalizado el tiempo acordado, por lo general una vez concluida la campaña ${ }^{20}$. En este proceso, la gran favorecida era la nobleza local, que acaparaba los puestos en la oficialidad beneficiándose de una «rápida profesionalización en la carrera militar» ${ }^{21}$.

Sin embargo, con el cambio dinástico la situación era otra: el peso de las operaciones volvía a caer en Cataluña, pero esta vez el enemigo no era Francia, y Navarra no se encontraba amenazada en su frontera pirenaica. En esa tesitura, las Cortes eran convocadas en el verano de 1705. Se iniciaban así las conversaciones para el servicio en hombres que debía aportar el reino para la defensa de la monarquía, mostrándose de nuevo la «interesada generosidad» por parte de las élites navarras ${ }^{22}$, sabedoras de las necesidades de Felipe V. Una posición de ventaja que, en cualquier caso, no cuestionaba la lealtad dinástica. El joven rey juraba respetar los fueros, y no violentaba la situación de Navarra en el esquema de la Monarquía. Felipe V, desde la óptica navarra, escrupulosamente legalista, era el monarca legítimo, y el proceso negociador que se abría lo hacía dentro del mantenimiento y aceptación del orden establecido ${ }^{23}$.

Ruta de paso para las tropas, Navarra se veía una vez más condicionada por su emplazamiento a caballo entre España y Francia, y en el mapa mental de sus clases dirigentes no cabía la posibilidad de plantearse un corrimiento político: el mantenimiento del statu quo que tanto les beneficiaba corría paralelo a la suerte de Felipe V. La obviedad geográfica, los intereses económicos y las posibilidades de promoción que se vislumbraban hicieron del Reino refugio borbónico, dentro de su marco de garantías constitucionales. Navarra prestaba una fidelidad negociada, pero incondicional.

\section{LAS CORTES DE SANGÜESA ANTE EL RECLUTAMIENTO}

Las Cortes de Navarra fueron reunidas en Sangüesa a comienzos de junio, para, en palabras del virrey marqués de Solera, «haceros presentes las necesidades con que S. M. se halla de gente y dinero para defender a España del furor y la herejía $»^{24}$. No obstante, la cuestión de fondo no entraba en escena, dirimiéndose cuestiones menores $^{25}$. El 8 de julio se leía una carta del monarca en la que planteaba dos posibilidades al Reino: o bien un servicio consistente en dos regimientos reclutados, uniformados, armados y mantenidos a costa del Reino -responsabilizándose la Hacienda real del pan de munición-, o bien cuatro regimientos costeados por la

20. Ostolaza Elizondo, 1999: 265-276; Martínez ArCe, 1999: 44-47; Martínez ArCe, 2002: 27; Floristán IMÍzCOZ, 2015: 81-107.

21. Rodríguez Garraza, 2007: $367-387$

22. FLORISTÁN IMİZCOZ, 1991: 197.

23. Sesé Alegre, 1988: 193-204.

24. ARGN, Actas Cortes, Lib. 5, f. 335r. Sangüesa, 02-06-1705. Proposición del señor virrey a los Tres Estados, Sangüesa. Dicha instrumentalización del componente religioso es común en ambos bandos (González Cruz, 2004: 217-233).

25. Las cuales se recogen en el «Cuaderno de las leyes y agravios reparados a suplicación de los tres estados del Reino de Navarra en las Cortes del año de 1705...», RAH, 14/9156(2). 
Monarquía. Bajo la primera condición, estos debían presentarse en Corella el 25 y el 3 I de agosto, mientras que si se dejaba en manos de la Corona el reclutamiento de los cuatro regimientos tenían que llegar a dicha plaza de armas de manera escalonada entre el ro y el 25 de agosto. En ambos casos, las tropas debían ser conducidas hasta Corella por cuenta del Reino, y allí se les proporcionarían armas y uniformes para ser enviados «a las partes que más conviniere» ${ }^{26}$. Un detalle que dejaba entrever la incertidumbre en torno a la evolución de la guerra en España a lo largo del verano de I705, en especial a partir del desembarco aliado en agosto ${ }^{27}$. Un aspecto, no obstante, común a los ejércitos europeos, fruto de la improvisación inherente, por la cual variaba en muchas ocasiones el destino de los regimientos una vez reclutados y enviados al frente ${ }^{28}$.

Cada regimiento constaba de doce compañías de cincuenta soldados, dos tambores, dos sargentos, un alférez, un teniente y un capitán, siendo el coronel y el teniente coronel también capitanes de sus compañías; amén de un sargento mayor, dos ayudantes, un capellán, un cirujano y un preboste. La carta incluía asimismo que cada sargento mayor debía llevar un recuento de sus hombres. Una de las preocupaciones de la nueva monarquía era el conocimiento de sus propias fuerzas, las cuales desconocía con exactitud, un detalle que resultaba preocupante. Esta cuestión saltaba a la palestra y se unía al tradicional recelo en torno a la opacidad que rodeaba al número de tropas con las que contaban los regimientos, cuestión que había comenzado a centralizarse en torno a la Tesorería Mayor de Guerra en la figura de los pagadores ${ }^{2}$. Las deserciones y bajas afectaban al funcionamiento interno de las localidades de origen de los desertores, que tenían que reponer al fugitivo o colaborar en su captura, y perjudicaban los intereses personales de los oficiales, que veían mermado el retorno de su inversión, una situación que fomentaba la corrupción y era un problema enrocado en el conjunto de los ejércitos europeos, manifestado entre la soldadesca ${ }^{30}$ y la oficialidad ${ }^{31}$.

El I3 de julio se leía la carta de Felipe $\mathrm{V}$ a las $\mathrm{Cortes}^{32}$, y al día siguiente se votaba por primera vez sobre el real servicio, rechazándose ambas propuestas. Comenzaba una negociación contrarreloj. Dos días después, se leía en Sangüesa una carta enviada por el virrey Solera insistiendo en la inminencia de la campaña de Portugal y en las noticias de que se aproximaba una armada Aliada, información corroborada por don Juan Esteban de Cegama, agente del Reino en Madrid ${ }^{3}$. Sin embargo, no

\footnotetext{
26. ARGN, G., leg. 5, C. 71, Madrid, 08-07-1705. Felipe V a las Cortes.

27. Francis, 1975: 152-197; Hugill, 1991: 147-193; Albareda Salvadó, 2002: 72-76; Falkner, 2015: 95-100.

28. ChAGNIOT, 2001: 109-112.

29. De Castro Monsalve, 2004: 74-75.

30. Entre 1700 y 1763 una quinta parte de los soldados franceses desertó (CORVISIER, 1958, 736-737), y el resto de los estados europeos presentaban cifras similares (BERKVICH, 2017, 55-74). Era habitual que muchos de estos reclutas que habían desertado se realistasen en otras unidades para cobrar una nueva prima de enganche. CHILDS, 1987: 104-105. Un soldado inglés, condenado por desertor en 1707, confesaba haber ganado sesenta libras alistándose en distintos regimientos, DAVIES, 1950: 146-159.

31. Este tipo de prácticas afectaban también a la oficialidad europea, alistando incluso falsos soldados si había revista, los «passe-volants», pues los ingresos de los oficiales dependían en gran medida del número de tropas con el que contase su regimiento (LEWIS, 1957: 126-135; DrÉVILLON, 2005: 103-109).

32. ARGN, Actas Cortes, Lib. 5, f. 359v. Sangüesa, 13-07-1705.

33. ARGN, Sección de diputados y..., leg. 3, c. 19, Madrid, 18-07-1705. Cegama a las Cortes.
} 
era hasta el 2I de julio cuando el marqués de Solera recibía la noticia de que el Reino había resuelto servir con tres regimientos de seiscientos hombres durante el tiempo que durase la guerra, equipados y pagados por la Corona. El virrey era consciente de la dificultad de alcanzar el objetivo inicial, en especial por el coste de «los largos servicios modernos», y por la falta de hombres. La correspondencia entre Solera y Grimaldo muestra así sensibilidad y realismo, dentro de la urgencia del servicio, de lo cual se deduce cierta habilidad en la propuesta inicial de Madrid, comenzando la negociación por lo alto, sabedores de que «el servicio de tres regimientos no se ha hecho en ninguno de los siglos pasados» ${ }^{34}$. La mañana del miércoles 22 , se resolvía el bando que debía publicarse en las localidades navarras, anunciando las penas a las que se enfrentaban los hombres que habían comenzado a huir a Francia, Guipúzcoa, Álava o Castilla, apelando a las graves consecuencias de las deserciones, que forzaban a recurrir a hombres casados, dejando en situación de desamparo a sus familias. Se les daba ocho días para volver so pena de ser encarcelados en Pamplona y a continuación ser destinados a los temibles presidios de África ${ }^{35}$.

Finalmente, se concluían las condiciones del real servicio ${ }^{36}$. En ellas las Cortes establecían una solución intermedia, sirviendo a Felipe $\mathrm{V}$ con tres regimientos vestidos, armados y pagados por S. M., con la única obligación de trasladar las tropas hasta la localidad de Corella. Las condiciones, aceptadas por el virrey, evidenciaban la necesidad de efectivos. Estos soldados tenían que ser naturales o «habitantes en este reino como sean españoles». La oficialidad, navarra, era nombrada por el Reino. Las autoridades locales se hacían cargo del coste de la recluta y de la conducción hasta Corella, siendo el socorro diario de un real, y de dos libras de pan, por soldado. Las tropas debían servir dentro de los límites de España. En el caso, muy probable, de producirse fugas, se añadía que las localidades de origen no tenían la responsabilidad de sustituir a dichos hombres, aun cuando se diesen las órdenes para ello, claudicando la Monarquía en tan sensible cuestión. Si huía antes de llegar a Corella, las penas eran de veinticuatro ducados, quedando condenados a servir en presidio en el frente de Portugal, y a compensar con dos partes de dicha pena pecuniaria para su reemplazo y la tercera para el denunciante, y de darse a la fuga una vez formados los regimientos de dos años de destierro. El 5 de agosto la carta de Felipe $V$ en la que el monarca agradecía el servicio prestado era leída por Francisco de Aperregui, oidor del Consejo del Reino de Navarra. Ese día, Solera comunicaba a los brazos que ya tenía en su poder las patentes en blanco para el nombramiento de oficiales «para entregarlas como pareciere» a las Cortes, instando a la puntualidad ante la necesidad de enviar refuerzos hacia Aragón ${ }^{37}$. Miguel Jerónimo de Aranguren, secretario de los Tres Estados, certificaba, un mes después de iniciarse el proceso, las condiciones del servicio confirmadas por Felipe V.

34. AHN, E., leg. 273, Pamplona, 21-07-1705. Solera a Grimaldo.

35. ARGN, G., leg. 5, c. 72, Pamplona, 22-07-1705. Solera a las Cortes. Este tipo de penas eran comunes, pese a que, ante la escasez de hombres, se mostraba una mayor flexibilidad, primando su reincorporación al ejército, Torres Aguilar, 2001: 541-557.

36. AHN, E., leg. 273, Sangüesa, 22-07-1705. El Reino a Felipe V.

37. AHN, E., leg. 273, Pamplona, 05-08-1705. Solera a las Cortes. 
El ambiente se vería enrarecido con la llegada de Bartolomé Ladrón de Guevara, capitán de las Reales Guardias Españolas, con la intención de reclutar voluntarios, pues se pretendía aumentar en un regimiento las Reales Guardias. Comenzaban los quebraderos de cabeza para el marqués de Solera, interlocutor entre Madrid y las Cortes, quien proponía una solución intermedia por la cual se integrase uno de los regimientos navarros en la Guardia Real, en línea con las condiciones del servicio que daban libertad de continuar en el ejército una vez terminado el conflicto. El Reino intervenía arguyendo que aquella partida interferiría en la leva, bloqueando este reclutamiento paralelo ${ }^{38}$, si bien las Guardias Españolas serían el destino, al menos parcialmente, del esquivo tercer regimiento ${ }^{39}$. La precipitada aceptación de las condiciones para el servicio sembraba de dudas la Secretaría de Guerra, y Grimaldo se dirigía a comienzos de agosto a las Cortes desdiciéndose parcialmente a través de una carta firmada por el monarca. El ministro se arrepentía de las facilidades dadas a Navarra, temiendo una recluta de pésima calidad, proclive a la deserción, sin entrenamiento y lejos de la supervisión real hasta el momento de su entrega, no responsabilizándose las autoridades navarras por ello ${ }^{40}$. El virrey Solera, en una posición incómoda, reiteraba a las Cortes la necesidad de conservar dichos regimientos completos si no querían que estos se desintegrasen, insistiendo en traspasar uno de esos regimientos a las Guardias Reales, a lo cual las Cortes se negaban de forma tajante, al entender que esto implicaría problemas en la recluta de los tres regimientos - por ejemplo, incentivando a los reclutas a enrolarse en dicho regimiento en detrimento de los cuerpos levantados por el Reino- ${ }^{41}$. A ello se añadía la propia situación de espera, con el coste que esto suponía ${ }^{42}$. La presión sobre el virrey aumentaba un día después, al recibir una carta desde Sangüesa en la que los tres brazos mostraban su preocupación por el aumento de la inseguridad al estar los caminos «llenos de ladrones de los que andan fugitivos», haciendo hincapié en los daños que esto podía causar ${ }^{43}$.

El mensaje era claro: una vez aprobado el servicio de tres regimientos y acordado el repartimiento, el Reino daba la negociación por concluida, y cualquier variación implicaba riesgos que la Monarquía no podía permitirse si quería asegurar el cordón umbilical que la unía a Francia. El repartimiento por ciudades y villas quedaba conforme a la población ${ }^{44}$. La estimación de 32.630 vecinos del último apeo daba una cifra de algo más de 150.000 habitantes ${ }^{45}$, no olvidando que su distribución era desigual y debía repartirse la responsabilidad por merindades. Sin grandes ciudades que ejerciesen de imán, el servicio aprobado en Cortes no podía ser satisfecho con

\footnotetext{
38. AHN, E., leg. 273, Sangüesa, 29-07-1705. El Reino a Grimaldo.

39. Andújar Castillo, 2009: 175-196.

40. ARGN, G., leg. 5, C. 75, Madrid, 06-08-1705. Grimaldo a las Cortes.

41. Se trataba de una corrupción del sistema frecuente en los ejércitos europeos, siendo estos potenciales «rouleurs» en el caso que nos ocupa un problema para los intereses creados en torno a los regimientos levantados por el Reino, al, presumiblemente, fomentar la deserción hacia la unidad de las guardias reales que pretendía levantarse.

42. AHN, E., leg. 273, Pamplona 11-08-1705. Solera a Grimaldo.

43. ARGN, Actas Cortes, Lib. 5, f. 396v.

44. ARGN, G., leg. 5, c. 77.

45. ARGN, Actas Cortes, Lib. 5, f. 369v. Esto concuerda con las 36.200 familias contabilizadas en 1700, FLORISTÁN IMízCOZ, 1985: 205-234.
} 
voluntarios, y alcanzar la cuota fijada presentaba dificultades $4^{46}$. Incluso los regidores de Pamplona se vieron en la necesidad de publicar un bando, instando a los priores de cada barrio para que, distribuidos por gremios, «por auto público», pasasen revista a los vecinos ${ }^{47}$. Conscientes de que era necesario estimular el alistamiento voluntario, se les ofrecía cincuenta reales por enrolarse, dieciocho de socorro diario y dos reales por día que durase el trayecto hasta Corella. Meses después el ayuntamiento se reconocía incapaz de pagar los io.89o reales que le habían supuesto los gastos de la leva y la conducción de los hombres hasta la plaza de armas. Ante la imposibilidad de poder asumir las deudas, la ciudad se veía obligada a pedir permiso al Real Consejo para tomar a censo I.0oo ducados sobre el expediente de los 500 ducados de las tierras y aguas, hipotecando las rentas de los próximos ejercicios ${ }^{48}$. Mediante esta gestión municipal del reclutamiento, se cumplía con lo estipulado en Cortes, pero a un alto coste.

Imparable, la guerra se acercaba. No sería hasta el i8 de agosto, mes y medio después de leerse la petición de servicio de Felipe V, cuando las Cortes votaban a Joaquín de Ripalda, I conde de Ripalda ${ }^{49}$, a don Francisco Ignacio de Mencos, y a Miguel de Senosiáin como coroneles de los tres regimientos, y hasta los días siguientes no se completarían las plantas de estos. Solera no podía sino desahogarse en una carta escrita el día I9, lamentando «estar perdiendo el tiempo», a vueltas con «las instancias que el Reino me daba con motivo de sus excesivos gastos» y el presunto peligro que suponían quienes al parecer estaban dándose a la fuga ${ }^{50}$. En las siguientes sesiones se votaban de conformidad los capitanes de las compañías restantes. La elección de lugartenientes de capitanes y sargentos y de los demás cargos se dejaba a los capitanes, y a los coroneles el nombrar a los prebostes. Las Cortes por lo tanto acaparaban el nombramiento de la plana mayor y de la oficialidad de los regimientos salvo en el caso de los capitanes de granaderos, reservado al virrey. La falta de experiencia de algunos beneficiarios de las patentes y sus lazos familiares dentro del brazo militar nos dejan entrever el cerrado coto que suponía el acceso a puestos en la oficialidad ${ }^{\mathrm{s}}$.

El 26 de agosto los brazos comunicaban a Solera la concesión de 6.00o ducados a pagar en tres años, un servicio en dinero que se añadía al servicio en hombres, los cuales deberían estar en Corella para el 20 de septiembre. A continuación, eran nombrados los representantes para hacer la entrega en Corella, con la instrucción

\footnotetext{
46. Por ejemplo, la ciudad de Estella presentaba en sus cuentas «6oo ducados gastados en los 58 soldados puestos a costa de la ciudad en Corella». AME, Libro de cuentas, vol. 55.

47. AMP, Libro de actas, $n^{\circ} 24$, f. 318, 24-07-1705

48. AMP, Libro de actas, $n^{\circ}$ 25: 1-2, 03-11-1705.

49. Esteban Joaquín Ripalda y Marichalar pertenecía a una familia de tradición militar. Presentaba una más que digna hoja de servicios. Durante un cuarto de siglo había sido soldado, alférez y capitán en África, Cataluña y Extremadura, y en la campaña de 1705 protagonizaría una acción heroica en Fraga. Con las armas de fuego inutilizadas por la lluvia, comandó una carga a bayoneta, siendo herido de dos balazos. Sería trasladado a Zaragoza, y escaparía a Pamplona tras la pérdida de Aragón, «teniendo por menor mal el daño que le podía resultar del viaje, que el de vivir entre desleales a V. M.», tal y como dice en su memorial, solicitando el grado de brigadier. Precisamente sus habilidades para la fuga serían compartidas por sus soldados, aunque, como veremos, en otras circunstancias. AHN, E., leg. 286, 09-12-1706.

50. AHN, E., leg. 273, Pamplona, 19-08-1705. Solera a Grimaldo.

51. Andújar Castillo, 2004: 54-55.
} 
de proceder hasta formar cada regimiento, para que «sin dilación alguna, se haga el asiento en los libros reales y los soldados sean admitidos a sueldo de S. M.» $\aleph^{52}$, con una ayuda de costa estipulada en tres ducados diarios ${ }^{53}$. La respuesta de las Cortes al virrey, a 27 de agosto, no invitaba al optimismo. Remarcaban la necesidad de aplazar la entrega de las tropas por las dificultades para alimentar a los hombres que se encontraban hacinados, los cuales caían enfermos fruto del calor extremo y las malas condiciones higiénicas, en perjuicio del servicio, de los municipios que tendrían que sustituirles y de la calma aparente de la que gozaba Navarra ${ }^{54}$. Pese a ello, el balance, al menos en un primer momento, parecía exitoso: las Cortes habían concedido tres regimientos, un año de cuarteles y alcabalas, y 6.ooo ducados -consignados al reclutamiento y manutención de los regimientos ${ }^{55}$, a pagar en tres años; tal y como el monarca reconocía y agradecía al Reino ${ }^{56}$. Quedaba por ver la eficacia del Reino en la aplicación de dicho servicio.

\section{EFICACIA PUESTA A PRUEBA: EL CAMINO HACIA EL FRENTE}

Para el marqués de Solera, el proceso se dilataba, atrapado en la telaraña foral. Los representantes navarros parecían los únicos que no alcanzaban a ver la gravedad de los acontecimientos. El goteo de desertores no parecía sino la evidencia de que, a nivel popular, el sentimiento de urgencia ante una amenaza de guerra real crecía semana a semana. Tan solo un día después de la advertencia realizada por las Cortes al virrey, dejando caer un aumento de la inseguridad en Navarra, se interceptaba en Zaragoza una carta. El supuesto autor era Jorge de Hesse, y los destinatarios eran los diputados del Reino de Aragón. En ella se prometía, frente al «fuego de guerra ocasionado por la violencia francesa» acabar con la esclavitud a la que se había visto reducido Aragón y "restaurar la honra de la nación española» ${ }^{57}$. Ese mismo día, el obispo de Lérida enviaba una carta desesperada a Zaragoza, describiendo el pésimo estado de las defensas. La guarnición se reducía a tres compañías, unas pocas decenas de hombres. Temía que los grupos de guerrilleros, amenazando a los campesinos con quemar los campos, avanzaran sin oposición hasta Lérida ${ }^{58}$. En esos momentos se tomaba declaración a un desertor irlandés recién llegado. Dado a la fuga tras desembarcar en Barcelona, relataba cómo los Aliados habían desembarcado I6.00o efectivos, de las cuales unos 2.000 habían enfermado durante el trayecto ${ }^{59}$. Con todo, resultaba una cifra angustiosa para el obispo de Lérida, y mareante para el renqueante esfuerzo bélico navarro.

52. ARGN, G, leg. 5, carp. 80, Sangüesa, 29-08-1705. Las Cortes a sus representantes.

53. ARGN, Actas Cortes, Lib. 5, f. $411 \mathrm{v}$

54. ARGN, Actas Cortes, Lib. 5, f. 409v-409r.

55. ARGN, Cuarteles y alcabalas, leg. 3, carp. 30, 26-08-1705.

56. ARGN, Cuarteles..., leg. 3, carp. 38, 15-09-1705.

57. AHN, E., leg. 264, 14-09-1705. Carta de Jorge de Hesse a bordo del navío Namur a los diputados de Aragón.

58. AHN, E., leg. 264, 14-09-1705. El obispo de Lérida al arzobispo de Zaragoza.

59. AHN, E., leg. 264, 15-09-1705. Declaración de Felipe Juan, desertor irlandés. 
El conde de Gormaz, angustiado por la correspondencia que mantenía con Francisco de Velasco, virrey de Cataluña, disponía que, amén de formar un regimiento con los desertores irlandeses que llegaban a Aragón, era necesario que los regimientos navarros se pusiesen en marcha hacia Lérida el día 2I, dando por supuesto que el día 20 se encontrarían en Corella, con la esperanza ulterior de que se unieran en el campo de Tarragona al ejército que bajaba por Aragón y el que desplazaba desde $V_{\text {Valencia }}{ }^{60}$. Había llegado ya a Corella el barón de Winterfeld, mariscal de campo y teniente coronel de las Guardias Valonas, bajo cuyo mando habían de estar las tropas que se encaminaban a Lérida. La falta de sincronización entre el avance imparable de los Aliados por Cataluña y el proceso de reclutamiento y reunión en la plaza de armas de Corella era alarmante. El 24 de septiembre, Solera informaba de que las tropas iban llegando de manera desordenada, y que por lo tanto los funcionarios reales encargados de la contabilidad sólo habían podido conformar el primer regimiento. Se esperaba permitir partir a la mañana siguiente al segundo, y para el final de la semana al tercero ${ }^{6 r}$.

Winterfeld había llegado a Corella el domingo, día 20, y se encontraba con la frustrante situación de no hallar los regimientos preparados. El día de su llegada habían arribado seiscientos reclutas conducidos por los diputados encargados de su traslado. Al día siguiente se habían distribuido los uniformes y el armamento, y el miércoles Winterfeld pasaba revista, partiendo el regimiento de Ripalda hacia Zaragoza esa misma tarde, a 23 de septiembre, dos meses y medio después de leerse la carta de Felipe V en Sangüesa. Winterfeld había dado la orden de que Ripalda esperase la llegada del siguiente regimiento, salvo que el arzobispo de Zaragoza y virrey de Aragón juzgase inaplazable su envío al frente. Don Antonio Ibáñez de la Riva, de origen castellano, pese su experiencia -o tal vez a causa de ella- como virrey y capitán general de Aragón durante una primera etapa en tiempos de Carlos Il, se sabía un extraño, y desconfiaba de las milicias locales. Conocedor del caldo de cultivo austracista a través de las incautaciones de propaganda clandestina y de las detenciones, requería tropas de confianza ${ }^{62}$. En esos momentos, mientras la nobleza aragonesa levantaba atropelladamente compañías ${ }^{63}$, todavía se estaba formando el segundo regimiento en Corella, y el mariscal de campo borbónico estimaba que, para el sábado, día 26, podría pasarle revista y enviarlo hacia Zaragoza, dándose como plazo para mandar el tercer regimiento hasta el lunes 28.

La calidad de la recluta dejaba mucho que desear, y el absentismo de la oficialidad no podía ocultarse -para escepticismo de Winterfeld-, que daba un parte desolador:

«... dudo mucho si se sacará de estos regimientos la utilidad que se espera, pues, aunque son cumplidos en hombres y que sólo pudieran hallarse entre ellos alrededor de ciento que desechar, por pequeños y muchachos, como los más vienen forzados, temo que se hayan de huir muchos, mayormente faltando gran parte de los oficiales. En el primer regimiento

\footnotetext{
6o. AHN, E., leg. 264, Zaragoza, 16-09-1705. Gormaz a Velasco.

61. AHN, E., leg. 273, Corella, 24-09-1705. Solera a Grimaldo.

62. Borrás GUALIS, 1973: 43-49.

63. Gaceta de Madrid, núm. 40, 06-10-1705. San Felipe, 1725: 178.
} 
sólo se halla el conde de Ripalda. Su teniente coronel, sargento mayor y ayudante están en Barcelona. Don Francisco de Mencos, coronel del segundo regimiento, viene de Flandes y se espera presto. Su teniente coronel, sargento mayor y ayudante me dicen se hallan en Barcelona. No hay más que siete capitanes presentes, los demás se hallan en los ejércitos. El coronel del tercer regimiento, Miguel de Senosiáin, está en Andalucía; sólo se halla aquí su teniente coronel» ${ }^{6}$.

En todo el proceso, sólo la producción y el suministro de armas y uniformes habían sido exitosos, confiados no a las instituciones navarras sino al entramado de asentistas y funcionarios reales ${ }^{65}$. El responsable de la provisión de víveres al ejército en Navarra, José de Soraburu ${ }^{66}$, había pasado a finales de agosto a Bayona para recibir los uniformes de los tres regimientos y hacerse cargo del envío de estos a Corella, así como del armamento ${ }^{67}$. Soraburu había llegado a Corella un día después que Winterfeld, e informaba el 24 de septiembre haber cumplido con las instrucciones tras hacerse cargo de la logística necesaria para vestir y armar a dichos regimientos con los fusiles, bayonetas, munición y demás útiles producidos en las fábricas de Guipúzcoa. De la producción armamentística se había responsabilizado un celoso funcionario, Miguel Francisco Salvador ${ }^{68}$. Catalán borbónico, presentaba una extensa hoja de servicios, y tras encargarse de la provisión de los ejércitos en el frente extremeño, había pasado a su responsabilidad la supervisión de las reales fábricas de armas de Guipúzcoa situadas en Plasencia de las Armas, donde se producían las armas de fuego, y de Tolosa, en la que se fabricaban las armas blancas ${ }^{69}$.

Su desempeño como responsable de dichas fábricas y su implicación en la campaña adquiría un tono personal. Perdida Barcelona, era un exiliado más. Su compromiso con la causa resultaba impagable en el juego de espejos que era la lealtad a Felipe $V$, al igual que sus minuciosos informes en los que atestiguaba la calidad de las armas, producidas siguiendo los modelos de las muestras traídas desde Francia por encargo de Jean Orry. Así, se había conseguido fabricar en cantidades industriales material militar de igual calidad al empleado por el ejército francés ${ }^{70}$. En cuanto a los uniformes, Soraburu quedaba satisfecho con los asentistas franceses: chupas, calzones, medias, zapatos, sombreros, cinturones, camisas, corbatas y casacas. Había algunas «podridas y manchadas», de la misma manera que había ochenta fusiles

64. AHN, E., leg. 273, Corella, 24-09-1705. Winterfeld a Grimaldo. Irónicamente, Winterfeld desertaría al año siguiente, pasándose a la causa imperial, GUILLAUME, 1858: 430.

65. La carrera de Soraburu comenzó en la década de 1690 como proveedor de víveres para las tropas en Navarra y los presidios de Aragón y Guipúzcoa. En julio de 1705 se hacía con la conducción de uniformes y armamento entre Francia y Madrid, y, a continuación, comenzaría a ejercer como Tesorero de la Guerra en Navarra. RODRíGUEZ GARRAZA, 1996: 359-388

66. Guerrero Elecalde, 2011: 367.

67. AHN, E., leg. 273, Pamplona, 26-08-1705. Solera a Grimaldo.

68. Salvador presenta en 1706 una detallada relación de méritos, en la que narra sus «grandes hazañas para vestir decentemente un decreto y formar un título». AHN, E., leg. 305.

69. Recientes publicaciones han rebatido exitosamente el asentado prejuicio en torno al conservadurismo y retraso del ejército español frente a las nuevas técnicas armamentísticas, así como la supuesta precariedad de la producción armamentística. Storrs, 2013: 102-105; Herrero-QuesadA, 2015, 66-72; Rodríguez HernÁNDeZ, 2016a: $273-294$.

70. Detallando los precios de cada arma: fusiles a 46 reales y $3 / 4$ de vellón la unidad, carabinas a 41 reales y $3 / 4$ de vellón la pieza y pistolas a 27 reales de vellón. AHN, E., leg. 276, Plasencia de las Armas, 14-12-1705. Salvador a Grimaldo. 
rotos $^{71}$, pero el resultado era muy satisfactorio, una nota positiva que demostraba el correcto funcionamiento de la maquinaria bélico-administrativa borbónica.

Comenzaban a llegar a Zaragoza tropas procedentes de otros puntos de España destinadas a la recuperación de Cataluña, pero las noticias de la pérdida de Lérida forzaban a cambiar los planes iniciales, replanteándose así el papel de los regimientos navarros, cuyo objetivo pasaba a ser la localidad de Fraga ${ }^{72}$, en un momento en el que las partidas austracistas se internaban en Aragón hasta Bujaraloz. El marqués de Solera, testigo de tan disfuncional precampaña, se lamentaba de la falta de medios para pagar a oficiales y soldados. El virrey volvía a Pamplona a finales de mes desazonado tras enviar de vuelta a los comisarios para que «volviesen por mejores mozos de los que me presentaban», con escaso éxito ${ }^{73}$. El marqués de Solera sabía que el proceso de negociación y reclutamiento, así como su papel en la defensa de la Corona de Aragón, estaban abocados al fracaso.

Mientras el virrey volvía a Pamplona, en la localidad de Novallas, el capitán de compañía Manuel Antonio de Rada le escribía que sus hombres «antes se dejarán morir» que no recibir dos reales diarios, «siquiera uno». La solución no podía ser otra: «hasta que nos dure el dinero estamos prontos en gastar». Al menos, para de momento evitar las deserciones, tres esa misma noche de la compañía de don Francisco de Aristo $^{74}$. Nada más cruzar la muga entre Navarra y Aragón, se confirmaban los temores de Solera. La problemática de la deserción, incluso en un conflicto con cierta carga ideológica, como lo fue la Guerra de Sucesión, se repetía una y otra vez fruto de levas forzosas, falta de suministros y soldada, y derrotismo ante las adversidades ${ }^{75}$. En Fraga, el conde de Gormaz -ajeno a los problemas-, confiaba en alcanzar Lérida, seguro de que el primer regimiento navarro llegaría la noche del $30^{76}$. Ese día, los dos primeros regimientos llegaban a las inmediaciones de Zaragoza, donde el virrey-arzobispo se afanaba en reclutar tanto en la capital como en el resto del país, así como en recabar donaciones. Ni Gormaz ni los virreyes contaban con que ese día iban a desertar doscientos hombres del regimiento del conde de Ripalda. No sólo suponía un desastre en lo militar. Era un problema político, pues había que capturar a los desertores y castigarlos, sin caer en desafuero, y teniendo en mente que esos hombres eran mucho más valiosos de vuelta al frente que en presidio. La fórmula de dos años de destierro para los desertores y el perdón para todos los que se reintegrasen voluntariamente a sus cuerpos no podía ser más laxa ${ }^{77}$.

El envío de un humilde «ministro de la corte mayor» pueblo por pueblo, para recoger a los que se entregaban, era todo lo que podía ordenar el virrey, pasando a la Diputación de Navarra sus medidas ${ }^{78}$. Se confesaba en dicha carta «escarmentado», viendo cómo los municipios acogían a los desertores, ante una Diputación que se

71. AHN, E., leg. 297, Pamplona, 24-02-1706. Soraburu a Grimaldo.

72. AHN, E., leg. 264, 25-08-1705. Lorenzo Armengual, obispo auxiliar de Zaragoza, a Grimaldo.

73. AHN, E., leg. 273, Pamplona, 30-09-1705. Solera a Grimaldo.

74. AHN, E., leg. 273, Novallas, 30-09-1705. Los capitanes Aristo, Jarauta y Rada.

75. Duffy, 1988: 135-172; González Cruz, 2012: 65-90.

76. AHN, E., leg. 264, Fraga, 30-09-1705. Gormaz a Grimaldo.

77. AHN, E., leg. 273, Pamplona, 08-10-1705. Solera a Grimaldo.

78. ARGN, G., leg. 5, c. 81, Pamplona, 09-10-1705. Solera a la Diputación. 
ponía de parte de estos por las pésimas condiciones en las que se hallaban confinados en la ciudadela de Pamplona, y por considerar justificable su deserción del frente debido a la escasez de víveres y soldada. Esta cuestión iba a eternizarse, regateando la Diputación el número de fugitivos del regimiento de Ripalda -ahora I30-, y saliendo en intercesión de los desertores ${ }^{79}$. Los problemas planteados por la Diputación, tales como una soldada miserable, el agravio comparativo con el sueldo percibido en los demás regimientos, la falta de vituallas, acrecentada por la especulación que había llevado a una subida del precio del pan en Zaragoza, y la realidad de unos reclutas bisoños acostumbrados a la relativa comodidad de sus hogares, explicaban la deserción en tales números ${ }^{80}$. A finales de octubre, Solera se dirigía al arzobispo de Zaragoza comunicándole que, en coordinación con los intendentes franceses y de Guipúzcoa, esperaba reintegrar a más fugitivos, contando ya con treinta y seis presos que serían conducidos hasta la frontera ${ }^{8 \mathrm{I}}$.

El goteo de desertores capturados se alargaría durante meses, y su reincorporación al frente resultaría penosa. El virrey, a finales de noviembre, se lamentaba de que ni el arzobispo de Zaragoza ni el conde de Ripalda habían podido aportar jinetes para la conducción de los presos que se encontraban en la ciudadela de Pamplona, enviando sesenta y tres desertores, así como las armas y uniformes que se habían encontrado, al tiempo que llegaban a la ciudadela otros veinticinco fugitivos ${ }^{82}$. Aún a comienzos de 1706 seguían reenviándose soldados. El día 2 de enero, veintitrés de ellos eran despachados hacia el Reino de Valencia, donde se encontraban sus jibarizados regimientos ${ }^{83}$. Eran para estas alturas los fugitivos los que se entregaban, contando con el perdón real, en unos momentos críticos para el mariscal de Tessé, generalísimo de los ejércitos borbónicos, el cual acababa de vivir una preocupante revuelta en Zaragoza ${ }^{84}$. Resultaba improbable que estos alcanzasen Valencia, donde las tropas navarras, integradas bajo el mando del conde de las Torres, asediaban San Mateo y saqueaban Villarreal ${ }^{85}$. Las deserciones continuarían martirizando al virrey Solera hasta bien entrado $1706^{86}$. La Diputación, por su parte, no dejaría escapar el caso de Esteban de Vera, un vecino de Ardoiz que se había negado a delatar a algún posible desertor. Primero tomado prisionero, después liberado, ponía nombre a los abusos de poder de los oficiales reales, pues aun «suponiendo la Diputación que dichos alguaciles han obrado con orden superior», iba en contra de las condiciones

79. En honor a la verdad, el arzobispo de Zaragoza matizaba también el desastre, rebajando en cincuenta el número de huidos, lo cual no dejaba de ser una acción gravísima, «sin ninguna razón y tanto desprecio de sus jefes». Solera a Grimaldo, AHN, E., leg. 273, 08-10-1705.

80. AHN, E., leg. 273, 14-10-1705. El Reino a Felipe V.

81. AHN, E., leg. 273, Pamplona, 29-10-1705. Solera a de la Riva.

82. AHN, E., leg. 273, Pamplona, 26-11-1705. Solera a Grimaldo.

83. AHN, E., leg. 297, Pamplona, 02-01-1706. Solera a Grimaldo.

84. Pérez Álvares, 2010: 100-104.

85. El desempeño de las unidades navarras destinadas en la Cuenca del Cinca, recogido en el historial del Regimiento Navarra, Instituto de Historia y Cultura Militar, N. ${ }^{\circ}$ de caja 33, Legajo 1/037: 6-7. Es aquí donde fallece el coronel del tercer regimiento, Senosiain, cuyas tropas se refunden con el regimiento de Mencos, tal y como vemos en las propuestas para las vacantes surgidas en el Regimiento Navarra, en las que se propone a oficiales de dicho regimiento incorporados al Navarra. AHN, E., leg. 813, 26 de abril de 1707. Mencos a Tilly.

86. AHN, E., leg. 297, Pamplona, 05-02-1706. Solera a Grimaldo. 
del servicio, que garantizaba que los desertores debían ser castigados por los alcaldes o regidores de las localidades ${ }^{87}$.

Este tipo de situaciones no eran óbice para que Solera trasladase a la Diputación la obligación de levantar los cuatro regimientos de milicias para la propia defensa del Reino, aferrándose a que ésta era una regalía. Ante la negativa de la Diputación, el asunto llegaría hasta Madrid, donde Grimaldo conferenciaba con el marqués de Campollano, secretario de la Cámara de Castilla, sobre la legalidad de dicha leva. Campollano no albergaba dudas al respecto, y apenas tenía que remontarse a I689, cuando el virrey Bournonville dio orden de levantar los tercios de milicias, con las garantías emitidas por el Consejo de Guerra, órgano responsable de dicha medida por encima del Fuero General ${ }^{88}$. El reto para el virrey continuaba el 22 de junio del año siguiente, insistiendo en cumplir la orden, y en la necesidad de tener preparadas las milicias ante la eventualidad de verse obligado a defender las fronteras por una posible invasión desde Aragón. Pero el virrey hablaba solo. Agotado, se desdecía, derrotado: «será infructuoso» ${ }^{89}$. Pocos días después, fallecía repentinamente, de una apoplejía, el esforzado virrey, sobrepasado por los treinta batallones de infantería y veinte escuadrones de caballería que se estimaba tenían que cruzar Navarra de norte a sur, tras recibir la noticia de que las tropas francesas habían causado «repetidos excesos» entre la población civil $^{9 \circ}$. Un nuevo virrey, una nueva campaña de reclutamiento, una guerra que iba a llegar a Navarra, dejaban atrás al pundonoroso y eficiente marqués de Solera.

Mientras tanto, los regimientos navarros habían quedado acantonados en la cuenca del Cinca. Ripalda no podría hacer frente a las partidas austracistas que intentaban tomar Fraga, y sus hombres se verían obligados a retirarse a Barbastro a comienzos de noviembre. Sorprendidos por una partida austracista, «los navarros desampararon a su coronel, conde de Ripalda, que quedó malherido» ${ }^{91}$. La rebelión de Valencia arrastró consigo lo que quedaba de los regimientos navarros, integrados en un cuerpo mucho mayor, perdiéndose en la inmensidad de la guerra. La ruta, penetrando desde Alcañiz hacia Morella y Castellón, con el fin de cortar el paso a las tropas aliadas que descendían por Tortosa, resultaría tortuosa. Los informes redactados por el conde de las Torres nos muestran una campaña extenuante, acosados por las partidas de migueletes que infestaban los caminos, las lluvias torrenciales y la resistencia de los lugareños, quienes «repugnaban el rendirse», prefiriendo «ser fritos en aceite que ser vasallos de Felipe V». Los navarros supervivientes rompieron

87. ARGN, G., leg. 6, c. 2, 12-02-1706.

88. AHN, E., leg. 273, Madrid, 11-11-1705. Campollano a Solera.

89. AHN, E., leg. 297, Pamplona, 22-06-1706. Solera a Grimaldo.

90. En Navarra fueron motivo de queja los desmanes cometidos por soldados franceses en tránsito hacia el frente. La Diputación a Grimaldo, Pamplona. AHN, E., leg. 297, 13-07-1706. Las complejas relaciones entre los ejércitos en movimiento y la población civil preocupaban tanto al ejército borbónico como al austracista, necesitados de ganarse el favor de la población civil. GONZÁLEZ CRUZ, 2012: 131-144.

91. El conde de Robres fue testigo privilegiado de los acontecimientos. Robres era hermano de Miguel Pons de Mendoza, quien participó con su regimiento junto a Ripalda y acompañó posteriormente al conde de las Torres en la incursión hacia Castellón. Su relato de la guerra se refería a las tropas navarras desplegadas en Aragón como rápidamente reducidas «a cortísimo número y de poco provecho» mientras guarnecían Fraga. PONS de MENDOZA y De SALVÁ, 1882: 253-256. 
la disciplina impuesta por el conde de las Torres, saqueando Villarreal. El dramático relato dejado por de las Torres, en una lucha sucia, palmo a palmo, en la cual salvó a más de un millar de mujeres y niños, cuyos clamores «pudieran enternecer las piedras», dejaba un balance inicial estimado por el general de setecientos muertos, sin contar los que quedaban sepultados o abandonados en los tejados, continuando hacia Sagunto y Moncada, atravesando la huerta valenciana, definida por el conde como «un caos», con el fin de llegar a la capital ${ }^{22}$.

El asalto a Villarreal supuso un elevado número de bajas entre la oficialidad, lo que dejó en una situación de provisionalidad a los regimientos navarros. La revista de las tropas con las que contaba el ejército de Valencia a finales del mes de enero esclarece las dudas en torno a la supervivencia de los tres regimientos navarros, refundidos en un solo «Regimiento de Navarros», compuesto por 535 hombres, de los cuales 407 son soldados, 50 sargentos, 55 alféreces, 22 tenientes y un capitán, Mencos ${ }^{93}$. Un regimiento casi completo, sólo superado en número por los 675 de las Guardias Españolas y los 752 de las Guardias Valonas, pero que no era sino el resultado de la unión de los regimientos que salieron de Navarra a finales de septiembre del año anterior. Las terribles condiciones orográficas y meteorológicas, la necesidad de acantonar pequeños contingentes en las plazas que iban dejándose atrás, el acoso de las partidas de migueletes, y el peso de la campaña de Cataluña, que desviaba los recursos hacia Barcelona, hicieron añicos las posibilidades de reducir Valencia, pese a las continuas misivas del conde de las Torres, quien insistía en la importancia de tomar primeramente Valencia para a continuación envolver Cataluña. De las Torres, atormentado por evitar deserciones, confesaba verse obligado a ejecutar diversiones con los saqueos como reclamo para conservar a sus hombres, «por el cebo que tenían de pillaje», ante la falta de socorros ${ }^{94}$. El fracaso de la campaña de Cataluña cerró en falso el avance hacia Levante, adoptando el ejército borbónico una estrategia defensiva con el fin de conservar el territorio que se controlaba en el Reino de Valencia.

Meses después, en julio de I706, cuando se estaba perdiendo Aragón, se solicitaba el retorno de los navarros supervivientes, para defender el Reino. Las peticiones de cobertura realizadas desde Morella por Miguel Pons de Mendoza, demandando el refuerzo de trescientos navarros, nos permiten entrever un regimiento si cabe más disminuido que tan solo dos meses atrás ${ }^{95}$. El regimiento comandado por Mencos se hallaba acantonado en Alarcón a comienzos de julio, planteándose por parte del obispo de Cuenca su paso a Requena ${ }^{96}$. Sin embargo, pese a la inminente pérdida de la propia Cuenca, los navarros fueron destinados a Tarazona y Tudela ${ }^{97}$. El i6 de agosto llegaban a Tudela los reclutas supervivientes. Volvían a Navarra en una situación lamentable y sin haber recibido paga alguna desde el mes de

\footnotetext{
92. AHN, E., leg. 296, Campo de San Mateo, 16-01-1706, leg. 296. El conde de las Torres a Grimaldo.

93. AHN, E., leg. 296, Revista pasada en campo de Moncarday a las tropas borbónicas a 23 de enero.

94. AHN, E., leg. 2902, campo de Cheste, 28-02-1706. Torres a Grimaldo.

95. AHN, E., leg. 281, Morella, 24-03-1706. Pons de Mendoza a Grimaldo.

96. AHN, E., leg. 522, Cuenca, 02/07/1706. El obispo de Cuenca a Grimaldo.

97. ARGN, G., leg. 6, c. 7, 03-07-1706.
} 
enero $^{98}$, siendo los propios vecinos los que incluso les proporcionaron ropa ${ }^{99}$. Los regimientos navarros permanecerían en el frente navarroaragonés durante el avance austracista sobre Madrid del verano de 1706 y participarían en el avance sobre Aragón y Cataluña posterior a la batalla de Almansa, teniendo una larga trayectoria en el seno del ejército español como los regimientos Pamplona y Navarra ${ }^{\text {Ioo }}$. Aquel era el resultado de la tensa negociación entre los representantes de la Monarquía $\mathrm{y}$ las instituciones navarras.

\section{CONCLUSIONES}

Si I706 fue el annus horribilis de Felipe V, el desastre ya estaba en marcha en los meses finales de i705. El papel jugado por Navarra había sido secundario, contribuyendo a regañadientes al esfuerzo bélico. No obstante, frente a la inercia de la asociación de la defensa de la foralidad con el austracismo, nos encontramos con una realidad mucho más compleja. Navarra no podía no ser felipista: los intereses comerciales transfronterizos de muchos navarros a ambos lados del Pirineo, la existencia de una importante colonia en Madrid con gran influencia en el entorno cortesano, y las ambiciones personales de las élites navarras, preexistentes al cambio dinástico, veían en la opción borbónica una solución natural ${ }^{\mathrm{Ior}}$. Al mismo tiempo, ello no impidió que dicha adhesión supiese explotar la debilidad del estado borbónico desde el pactismo y la presión constitucionalista sobre las autoridades de la Monarquía, tal y como encontramos en la actitud mostrada durante el esfuerzo reclutador de la campaña de I705. Al mismo tiempo, pese a su particularidad institucional, el Reino experimentó los mismos problemas que el conjunto de territorios que componían la Monarquía y habían levantado regimientos, o que la propia Navarra en los tercios con los que sirvió en el siglo XVII ${ }^{102}$. Bajo la pátina foral, encontramos en el reclutamiento institucional una serie de procedimientos -petición por parte de las autoridades de la Monarquía, negociación entre dichos representantes y élites locales, y reparto de patentes en blanco entre esa oligarquía local-, y problemas muy variados -mala calidad de la recluta, altas cifras de deserción, improvisación en campaña-, comunes a los regimientos que levantan territorios y ciudades en otros puntos de España, al tiempo que la Monarquía absorbe la dual «navarridad», jurídica e identitaria, regional y estatal, como venía haciéndolo durante el siglo $\mathrm{XVII}^{103}$. Se nos aparecen en el seguimiento de los regimientos levantados en las Cortes de Sangüesa de I705, por lo tanto, la vigencia de las instituciones propias navarras, forales, y la presencia de problemas comunes al conjunto de la Monarquía en el espacio de una guerra en la cual es necesario

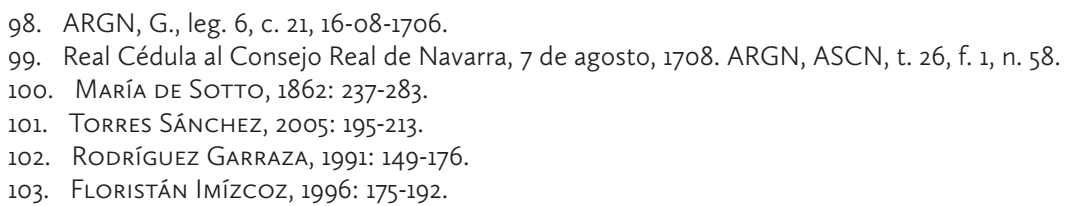


reclutar regimientos, los cuales, además, tendrán un largo recorrido, convertidos en los regimientos Pamplona, cuyo primer coronel sería el conde de Ripalda, y Navarra, cuyo coronel sería el conde de Mencos.

Este análisis del proceso de convocatoria de Cortes -cuyo evidente propósito es el de levantar una serie de regimientos para que estos entren a formar parte del ejército de Felipe $\mathrm{V}-$-, y posterior negociación, reclutamiento y puesta en campaña de dichas unidades nos permite no sólo analizar y presentar las relaciones entre Reino y Monarquía, sino además prestar atención a un aspecto escasamente investigado por la historiografía española como es la historia regimental, de especial dificultad al tener en la Guerra de Sucesión importantes ausencias documentales. Ambas aproximaciones - política e institucional, y militar, cruzando fuentes archivísticas nacionales y locales- integran al Reino y a sus regimientos en la Monarquía, y nos sirve para confirmar un recorrido común y no excluyente, así como para abrir un nuevo capítulo en el estudio de la Guerra de Sucesión en Navarra, al estudiar la implicación militar de dicho reino.

El marqués de Solera no viviría para verlo, pero su desempeño no fue, después de todo, ni inútil, ni «infructuoso», y es que, tal y como cantaban las lavanderas de Carabanchel:

«Navarra, no sólo ha estado

limpia en aquesta ocasión, sino que ha dado jabón, para lavar lo manchado, y es jabón aventajado para quitar manchas malas, porque es de bolas o balas... $»^{104}$.

104. BNE, ms. 2/50659(20), Madrid, 1706. 


\section{BIBLIOGRAFÍA}

Albareda, Joaquim, Felipe $V$ y el triunfo del absolutismo: Cataluña en un conflicto europeo (I700-I7I4), Barcelona, Entitat Autònoma del Diari Oficial i de Publicacions, 2002.

Albareda, Joaquim, La Guerra de Sucesión de España (I700-I7I4), Barcelona, Crítica, 2010.

ANdújar CASTILlo, Francisco, «La Guerra de Sucesión y los cambios en el ejército», en José Manuel González Beltrán (ed.), El asalto angloholandés de I702 a la bahía de Cádiz. Entre la política internacional y las repercusiones locales, Ayuntamiento de El Puerto de Santa María, 2013: 53-74.

Andújar CAstillo, Francisco, «El ejército de Felipe V: Estrategias y problemas de una reforma», en Eliseo Serrano Martín (ed.), Felipe Vy su tiempo, Zaragoza, Institución Fernando el Católico, 200I: 66I-682.

Andújar Castillo, Francisco, El sonido del dinero: Monarquía ejército y venalidad en la España del siglo XVIII, Madrid, Marcial Pons, 2004.

Andújar CAStillo, Francisco, «De la periferia a la Corte: la integración de vascos y navarros en los cuerpos de élite del ejército borbónico», en Rosario Porres Marijuán, Rosario e Iñaki Reguera (eds.), La proyección de la Monarquía Hispánica en Europa. Política, guerra y diplomacia entre los siglos XVI y XVIII, Bilbao, Universidad del País Vasco, 2009: I75-I96.

Angulo Morales, Alberto, «Militares en las fronteras imperiales del setecientos. El ejemplo de los regimientos de Cantabria y Navarra», en Érica Sarmiento; Marieta Pinheiro de Carvalho; Patricia Flier(orgs.), Movimientos, Trânsitos \& Memórias. Temas e Abordagens, Niterói, Asoec, 20I6: 98I-994.

De Artaza Montero, Manuel María, «Coyuntura crítica y cambio institucional: Felipe Vy Galicia», en María López Díaz (ed.), Galicia y la instauración de la Monarquía borbónica, Madrid, Sílex, 20I6: 2I-52.

Berkovich, llya, Motivation in War. The Experience of Common Soldiers in Old-Regime Europe, Cambridge University Press, 2017.

Borrás, Gonzalo M., La Guerra de Sucesión en Zaragoza, Zaragoza, Institución Fernando el Católico, I973.

Borreguero Beltrán, Cristina, «Del tercio al regimiento», Estudis: Revista de Historia Moderna, $\mathrm{N}^{\circ} 27$ (200I): 53-90.

De Castro, Concepción, A la sombra de Felipe V: José de Grimaldo, ministro responsable (I703I726), Madrid, Marcial Pons, 2004.

CÉNAT, Jean-Philippe, «Les enjeux géostratégiques et stratégiques sous Louis XIV», Hervé Drévillon, Bertrand Fonck y Jean-Philippe Cénat (eds.), Les dernières guerres de Louis XIV, Rennes, PUR, 2017: 47-6r.

Chagniot, Jean, Guerre et société à l'époque moderne, París, PUF, $200 \mathrm{I}$.

CHILDS, J., The British army of William III, I689-I702, Manchester University Press, I987.

MARía de SotTo, Serafín, conde de Clonard, Historia orgánica de las armas de infantería y caballería españolas, vol. XI, Madrid, Imprenta de D. B. González, I853.

Coloma García, Virginia, «Navarra y la defensa de la monarquía en los reinados de. Felipe III y Felipe IV», Príncipe de Viana, 204 (I995): I63-I82.

Contreras Gay, José, Las milicias provinciales en el siglo XVIII, Granada, Instituto de Estudios Almerienses, I993.

Contreras Gay, José, «El servicio militar en España durante el siglo XVII», Chronica Nova, 2I (I994): 99-I22. 
Coronas González, Santos M., Los juramentos forales y constitucionales de Felipe V en los Reinos de España (I700-I702), Madrid, Boletín Oficial del Estado, 2017.

CoRvisier, André, L'armée française, Paris, Presses Universitaires de France, I964.

DAviEs, G., «Recruiting in the Reign of Queen Anne», Journal of the Society for Army Historical Research, XXVIII (1950): I46-I59.

DrÉvILlON, Hervé, L'impôt du sang. Le métier des armes sous Louis XIV, París, Tallandier, 2005.

Duffy, Christopher, The Military Experience in the Age of Reason, Nueva York, Macmillan Publishing Company, 1988.

FaLKNER, J., The War of the Spanish Succession I7OI-I7I4, Barnsley, Pen \& Sword, 2015.

Floristán Imízcoz, Alfredo, «Evolución de la población de Navarra en el siglo XVII», Príncipe de Viana, I74 (1985): 205-234.

FloRistán Imízcoz, Alfredo, La monarquía española y el gobierno del Reino de Navarra, Pamplona, Gobierno de Navarra, I99I.

FLORISTÁN IMízcoz, Alfredo, «Entre la casa y la Corte: una aproximación a las élites dirigentes del Reino de Navarra (siglos XVI-XVIII)», José Imízcoz Beunza (dir.), Élites, poder y red social. Las élites del País Vasco y Navarra en la Edad Moderna, Zarauz, UPV, I996: I75-I92.

FloRistán Imízcoz, Alfredo, «Neoforalismo, nuevos fueros y conquistas. Navarra en la Monarquía de Carlos Il», Bernardo J. García García, y Antonio Álvarez-Ossorio Alvariño (eds.), Vísperas de sucesión. Europa y la Monarquía de Carlos II, Madrid, Fundación Carlos de Amberes, 2015: 8I-I07.

Francis, David, The First Peninsular War I702-I7I3, Londres, Ernest Benn Limited, I975.

Gilbert, A. N., «Army Impressment During the War of the Spanish Succession», The Historian, Aug I (1976): 689-708.

GonZAlez CRUz, David, «La 'demonización' del enemigo en el discurso bélico de la Guerra de Sucesión Española», en Alfredo Alvar; Jaime Contreras, y José Ignacio Ruiz (eds.), Política y cultura en la época moderna: cambios dinásticos, milenarismos, mesianismos y utopías, Universidad de Alcalá, 2004: 217-233.

GonZÁlez CRUZ, David, «Las deserciones en las fuerzas armadas españolas y extranjeras durante la Guerra de Sucesión: comportamientos y estrategias», Agustín González Enciso (ed.), Un Estado militar: España, I650-I820, Madrid, Editorial Actas, 2012: 65-90.

GonZÁlez Cruz, David, «Las fuerzas armadas españolas y extranjeras en el tratamiento a la población civil durante la Guerra de Sucesión», Manuel-Reyes García Hurtado (ed.), Soldados de la Ilustración, El ejército español en el siglo XVIII, Universidade da Coruña, 2012: I3I-I44.

GonZÁlez ENCISO, Agustín (2007), «Volver a la hora navarra», Agustín González Enciso (ed.), Navarros en la Monarquía española en el siglo XVIII, Pamplona, Eunsa, 2007; I3-60.

Guerrero EleCALDE, Rafael, Las élites vascas en el gobierno de la monarquía borbónica, Vitoria, Universidad del País Vasco, $201 \mathrm{I}$.

GUERRERo EleCALDE, Rafael, «Y la flor de lis brotó en las provincias vascas. Familias, fidelidad y servicios a Felipe V durante la Guerra de Sucesión (I700-I7I4)», en Roberto Quirós Rosado y Cristina Bravo Lozano (coord.), Los hilos de Penélope lealtad y fidelidades en la Monarquía de España, I648-I7I4, Valencia, Albatros Ediciones, 2015: 167-I78.

Guillaume, Gustave, Histoire des gardes wallones au service d'Espagne, Bruselas, F. Parent, I858.

Herrero Fernández-Quesada, María Dolores, VV. AA., Al pie de los cañones. La artillería española, Madrid, Ministerio de Defensa, 2015.

Hugill, J. A. C., No Peace Without Spain, Oxford, Kensal Press, I99I.

Lewis, W. H., The Splendid Century, Life in the France of Louis XIV, Prospect Heights, Waveland Press, I957. 
MAfFI, Davide, «El gigante olvidado. El ejército de Carlos II: entre la decadencia y la

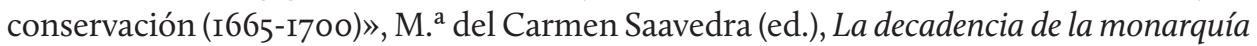
hispánica en el siglo XVII, Madrid, Biblioteca Nueva, 20I6: III-I28.

Martínez Arce, María Dolores, Navarra en tiempos de Carlos II «El hechizado», Pamplona, Gobierno de Navarra, I999.

Martínez Arce, María Dolores, Navarra y el ejército en el conflictivo siglo XVII, Pamplona, Bodegas Irache, 2002.

Martínez-Radío Garrido, Evaristo, «Levas y reclutas en la Asturias de la Guerra de Sucesión: el caso del Tercio del Principado», Revista de Historia Militar, (2008): I27-I66.

Martínez Ruiz, Enrique, Los soldados del Rey. Los ejércitos de la Monarquía Hispánica (I480I700), Madrid, Actas, 2014.

MuÑoz Rodríguez, Julio David, Felipe $V$ y cien mil murcianos. Movilización social y cambio político en la Corona de Castilla durante la Guerra de Sucesión (I680-I725), Universidad de Murcia, 20Ir.

Ostolaza Elizondo, María Isabel, Gobierno y administración de Navarra bajo los Austrias, Pamplona, Gobierno de Navarra, I999.

Pérez Álvarez, Maa. Berta, Aragón durante la Guerra de Sucesión, Zaragoza, Institución Fernando el Católico (CSIC), 2010.

RoBRes, Conde de, Historia de las guerras civiles de España, I700 - I708, Imprenta del Hospicio Provincial, Zaragoza, I882.

RODRíguez GARRAZA, Rodrigo, «Navarra y la administración central (I637-I648)», Cuadernos de Historia Moderna, $\mathrm{n}^{\mathrm{O}} \mathrm{II}$ (I99I): I49-I76.

Rodríguez Garraza, Rodrigo, «La Guerra de Sucesión en Navarra, I: Financiación y capitalización de asentistas autóctonos», Príncipe de Viana, 208 (I996): 359-388.

Rodríguez Garraza, Rodrigo, «Los intentos de extensión en Navarra del servicio militar (Siglo XVII)», Iura Vasconiae, 4 (2007): 367-387.

Rodríguez Hernández, Antonio José, «De Galicia a Flandes: reclutamiento y servicio de soldados gallegos en el ejército de Flandes (I648-I700)», Obradoiro de Historia Moderna, I6 (2007): 213-25I.

Rodríguez Hernández, Antonio José, «El ejército que heredó Felipe V: su número y su composición humana», en José Manuel de Bernardo Ares (coord.), La Sucesión de la Monarquía Hispánica, I665-I725. Biografías relevantes y procesos complejos, Madrid, Sílex, 2009: 265-296.

RODRíguez HeRnÁNDEZ, Antonio José, Los tambores de Marte: el reclutamiento en Castilla durante la segunda mitad del siglo XVII (I648-I70o), Universidad de Valladolid, 201 I.

RODRíguez HernándeZ, Antonio José, «¿Evolución o innovación? Los cambios técnicotácticos en el armamento del ejército español durante el relevo dinástico: nuevas consideraciones», Cuadernos de Historia Moderna, 4I(2) (2016a): 273-294. <http://dx.doi. org/IO.I420I/cuadieci20I4I547-72>.

Rodríguez Hernández, Antonio José, «Guerra y alianzas en la lucha por la hegemonía europea durante la segunda mitad del siglo XVIl. El papel de España», en Luis Ribot y José María Iñurritegui (Eds.), Europa y los Tratados de reparto de la Monarquía de España, I668-I700, Madrid, Biblioteca Nueva, 20I6b: 247-275.

Rodríguez Hernández, Antonio José, Díaz PARedes, Aitor, «Revisitando el neoforalismo: Reclutamiento en Navarra en tiempo de paz en la frontera (I659-I670)», en Rafael Torres Sánchez (ed.), Studium, magisterium et amicitia, Pamplona, Eunsa, 2018.

Rowlands, Guy (20II), «Moving Mars: The Logistical Geography of Louis XIV'S France», French History, Volume 25, Issue 4, 20II: 492-5I4. https://doi.org/IO.I093/fh/crro59 
SaAvedra Vázquez, María del Carmen, «La contribución de Galicia a la política militar de los Austrias y sus repercusiones políticas», en Antonio Álvarez-Ossorio Alvariño y Bernardo J. García García (eds.), La Monarquía de las naciones. Patria, nación y naturaleza en la Monarquía de España, Madrid, Fundación Carlos de Amberes, 2004.

SaAvedra Vázquez, María del Carmen, «La Guerra de Sucesión y sus efectos sobre la organización militar peninsular», Marina Torres Arce, Susana Truchuelo García (eds.), Europa en torno a Utrecht, Santander, Universidad de Cantabria, 2014.

SÁnCHEZ BelÉn, Juan Antonio, «La aportación de la Provincia de Álava a la contienda Hispano-Portuguesa en los años finales del reinado de Felipe IV (I663-I665)», Espacio, tiempo y forma, I2 (1999): 249-274.

SAN Felipe, Marqués de, Comentarios de la guerra de España e historia de..., Biblioteca Virtual Cervantes, 1725 .

SeSÉ Alegre, José María, «La Guerra de Sucesión (I700-I7I4). Aproximación al estudio del conflicto bélico en Navarra», Príncipe de Viana. Anejo, 9 (1988): 193-204.

Solbes FerRI, Sergio (I993), «Los servicios de las cortes de Navarra en el siglo XVIIl», José Ignacio Fortea López y Carmen $\mathrm{M}^{\mathrm{a}}$ Cremades Griñán (eds.), Política y hacienda en el Antiguo Régimen, Murcia, Universidad de Murcia, I993: 569-580.

Storrs, Christopher, La resistencia de la Monarquía Hispánica (I665-I700), Madrid, Actas, 2013. StORRs, Christopher, The Spanish Resurgence I7I3-I748, Yale University Press, 2016.

Torres Aguilar, Manuel, «El delito de deserción y la reforma del reclutamiento en el ejército de Felipe V», VV. AA., La Guerra de Sucesión en España y América. Actas X Jornadas de Historia Militar, Sevilla, 200I: 54I-557.

Torres SÁNCHEZ, Rafael, «La hora de los negocios. El triunfo económico de los navarros en el siglo XVIII», VV.AA., Juan de Goyeneche y el triunfo de los navarros en la monarquía hispánica del siglo XVIII, Pamplona, Fundación Caja Navarra, 2005: 195-213.

TORRES SÁnchez, Rafael, «Nuevos retos de la hora navarra», en Rafael Torres Sánchez (ed.), Volver a la «hora navarra». La contribución navarra a la construcción de la Monarquía española en el siglo XVIII, Pamplona, Eunsa, 2010: 9-32.

TORRES SÁNCHEZ, Rafael, Military entrepreneurs \& the Spanish contractor state in the eighteenth century, Oxford University Press, 2016.

UsunárIz GARAYOA, Jesús María, «Las instituciones del Reino de Navarra durante la Edad Moderna (I5I2-I808)», Revista internacional de los estudios vascos - Eusko ikaskuntzen nazioarteko aldizkaria, vol. 46, No. 2, (2001): 685-744. 

Monográfico - Special Issue: Política imperial y administración de industrias estratégicas: la Armada española en el largo siglo XVIII Imperial Policy and Strategic Industry Administration: the Spanish Navy in the Long Eighteenth Century

María Baudot Monroy, Manuel Díaz-Ordóñez \& IVÁN VALDEZ-BUbnov

Introducción / Introduction

\section{Agustín González Enciso}

Estado y empresa en la provisión de armas de fuego en el Siglo XVIII / State and Enterprises in the Supply of Firearms in the Eighteenth Century

\section{Manuel Díaz-Ordóñez}

El abastecimiento militar de cáñamo para el imperio español (16651808): globalización, estado y empresarios en el largo Siglo XVIII / Providing Hemp for Military Purpose for the Spanish Empire (1665-1808): Globalization, State and Entrepreneurs in the Long Eighteenth Century

\section{RAFAL B. REICHERT}

¿Cómo España trató de recuperar su poderío naval? Un acercamiento a las estrategias de la marina real sobre los suministros de materias primas forestales provenientes del Báltico y Nueva España (1754-1795) / How did Spain Tried to Recover his Naval Power? An Approach to the Strategies of the Royal Navy on the Supply of Forest Raw Materials from Baltic Sea and New Spain (1754-1795)

\section{José Manuel Vázquez Lijó}

Servir en la marina de Aranjuez en el Siglo XVIII: un destino deseado / Serving in the Navy in Aranjuez in the $18^{\text {th }}$ Century: A Desirable Destination

\section{IVÁN VALDEZ-BUBNOV}

Navíos para un imperio global: la construcción naval y la matrícula de mar en España, América y Filipinas durante el largo Siglo XVIII (1670-1834) / Warships for a Global Empire: Shipbuidling and the Maritime Registry in Spain, America and the Philippines during the Long Eighteenth Century (1670-1834)

\section{MARIA BAUdot MONROY}

La construcción de la Real Armada en Filipinas. Marinos españoles en Manila en la segunda mitad del siglo XVIII / Constructing the Spanish Royal Navy in the Philippines. Navy Officers in Manila during the Second Half of the Eighteenth Century

\section{Miscelánea · Miscellany}

\section{IVÁN LÁZARO URDIALES}

Las relaciones entre España y Rusia durante el reinado de Felipe V (1722-1742) / Relationships between Spain and Russia during the Reign of Philip V (1722-1742

\section{LEOPOLDINA LANDEROS DE CASOLARI \\ Controversias sobre el cosmógrafo Andrés García de Céspedes /} Controversies about the Cosmographer Andrés García de Céspedes

\section{Ainoa Chinchilla Galarzo \\ Portugal y la fallida paz con Francia: mediación española y corrupción francesa (1796-1800) / Portugal and the Failed Peace with France: Spanish} Mediation and French Corruption (1796-1800)

\section{Marcos Rafael Cañas Pelayo}

De una compañía comercial a la inserción en la élite cordobesa: los Fernández de Carreras (S. XVI-XVIII) / From a Trade Company to the Insertion in the Cordovan Elite: Fernández de Carreras's Lineage $\left(16^{\text {th }}-18^{\text {th }}\right.$ Centuries)

\section{Rumen Sosa Martín}

La sustitución lingüística del guanche en las Islas Canarias, un caso excepcional en la historia del mundo bereber / The Language Shift of Guanche Language in the Canary Islands, an Exceptional Case in the History of the Berber's World

\section{Aitor Díaz Paredes}

Fidelidad, fueros y negociación. Las Cortes de Sangüesa en la defensa de la Corona de Aragón (1705) / Loyalty, Fueros and Negotiation. The Cortes of Sangüesa in the Defense of the Crown of Aragon (1705)

\section{Taller de historiografía · Historiography Workshop}

\section{Ensayos · Essays}

\section{David Martín Marcos \\ La otra mirada de António Manuel Hespanha (1945-2019), In Memoriam /} An Alternative Gaze: António Manuel Hespanha (1945-2019), In Memoriam

333 Gabriel Astey

Virtud de la retorsión / Nobility of Contortion 


\section{Reseñas · Book Review}

345 Burke, Peter Hybrid Renaissance. Culture, Language, Architecture (ANTONIO URQUízar HeRRERA)

351 OLDS, Katrina B., Forging the past. The Invented Histories in Counter-Reformation Spain (JAVIER RodRíguez Solís)

357 Bolufer Peruga, Mónica, Mujeres y Hombres en la Historia. Una propuesta historiográfica y docente (JuLıo ARroyo VozMEDIANO)

361 Mira Caballos, Esteban, Francisco Pizarro. Una nueva visión de la conquista del Perú, (BeAtriz Alonso Acero)

367 Esteban Estríngana, Alicia (ed.), Decidir la lealtad. Leales $y$ desleales en contexto (siglos XVI-XVII) (José MigueL ESCRIBANO PÁEZ)

371 GaUdin, Guillaume, El Imperio de papel de Juan Díez de la Calle. Pensar y gobernar el Nuevo Mundo en el siglo XVII (JAVIER RUIZ IBÁÑEZ)

375 PASOLINI, Alessandra y PILO, Rafaella (eds.), Cagliari and Valencia during the Baroque Age. Essays on Art, History and Literature (FERNANDO CIARAMITARO)

381 SÁnCHEZ-Montes GonzÁLEz, Francisco, El viaje de Felipe IV a Andalucía en 1624. Tiempo de recursos y consolidación de lealtades (Francisco PREcioso IzQUiERDo)

385 Alimento, Antonella \& Stapelbroek, Koen (eds.), The Politics of Commercial Treaties in the Eighteenth Century: Balance of Power, Balance of Trade (FIDEL J. TAVÁREZ)

393 Marchena Fernández, Juan y Cuño Bonito, Justo (eds.), Vientos de guerra. Apogeo y crisis de la Real Armada (Pablo Ortega del Cerro) 